Revista Destaques Acadêmicos, Lajeado, v. 9, n. 2, 2017. ISSN 2176-3070

DOI: http://dx.doi.org/10.22410/issn.2176-3070.v9i2a2017.1366 www.univates.br/revistas

\title{
TRABALHO DE CONCLUSÃO DE CURSO NA GRADUAÇÃO EM EDUCAÇÃO FÍSICA - LICENCIATURA: SOBRE O QUE PESQUISAR?
}

\author{
Francis Taini da Silva Lopes ${ }^{1}$, Derli Juliano Neuenfeldt ${ }^{2}$
}

\begin{abstract}
Resumo: O estudo teve por objetivo identificar e analisar quais fatores influenciam acadêmicos de um curso de Educação Física - Licenciatura na definição da escolha do tema de estudo do seu TCC. Esta pesquisa caracteriza-se como descritiva, de cunho qualitativo. As informações foram coletadas mediante a realização de um questionário com 12 acadêmicos de um curso de Educação Física - Licenciatura do RS/BRA, todos matriculados no semestre 2016B, na disciplina de Estudos Dirigidos para Conclusão de Curso ou no Trabalho de Conclusão de Curso. Evidenciou-se que os acadêmicos fazem a escolha do tema baseados na sua história de vida, na identificação pessoal com o assunto e, também, por buscarem conhecimentos que pretendem utilizar futuramente no campo profissional.
\end{abstract}

Palavras-chave: TCC. Iniciação à Pesquisa. Conhecimento. Educação Física.

\section{INTRODUÇÃO}

O contexto universitário se caracteriza por valorizar e produzir conhecimento científico. Na instituição de ensino superior na qual se realizou essa pesquisa, a preocupação com o conhecimento científico está expressa na Missão Institucional, na qual consta como propósito: "Gerar, mediar e difundir o conhecimento técnico-científico e humanístico, considerando as especificidades e as necessidades da realidade regional, inseridas no contexto universal, com vistas à expansão contínua e equilibrada da qualidade de vida" (INSTITUIÇÃO, 2014, p. 04).

O conhecimento científico está presente nos programas de pósgraduação, mas, também, nos cursos de graduação, pois, a maioria, solicita

1 Graduação em Educação Física, Licenciatura. Univates. franci_lopest@hotmail.com.

2 Doutor em Ciências: Ambiente e Desenvolvimento. Coordenador do Curso de Educação Física do Centro Universitário UNIVATES. derlijul@univates.br. 
ao graduando a elaboração de um projeto de pesquisa e sua efetivação como condição para a conclusão do curso. Esse exercício de investigação é conhecido como Trabalho de Conclusão de Curso (TCC). O TCC é uma iniciação dos graduandos no campo científico, que visa aprofundar conhecimentos sobre um tema e contribuir na formação profissional. Situado no currículo nos últimos semestres do curso, o TCC é elaborado em forma de artigo ou monografia. A pesquisa emerge a partir de um problema, de uma inquietação. Dessa forma, uma dúvida recorrente entre acadêmicos que vão realizar o TCC é: o que pesquisar?

Durante a graduação, os acadêmicos têm contato com saberes de diferentes áreas de conhecimento por meio do ensino, de atividades de pesquisa e de extensão. Além disso, conhecem os campos de atuação por meio dos estágios curriculares. Dessa forma, este estudo problematiza fatores que influenciam os acadêmicos de um curso de Educação Física, Licenciatura, na definição do tema de pesquisa do TCC.

A estrutura curricular do curso investigado tem duração de oito semestres e carga horária de 3.240 horas. O TCC começa na disciplina de Estudos Dirigidos para Conclusão de Curso ( $7^{\circ}$ semestre), disciplina específica do curso de Educação Física, na qual os acadêmicos elaboram um projeto de pesquisa e o submetem a uma banca de especialistas da área do tema de estudo. No TCC ( $8 .^{\circ}$ semestre), desenvolve-se a parte aplicada da pesquisa e elabora-se como produto final um artigo científico, que novamente é avaliado por uma banca.

Ao longo dos 17 anos do curso investigado, já se experimentaram duas formas de conduzir o TCC. Inicialmente, a disciplina de Estudos Dirigidos para Conclusão de Curso era ministrada por apenas um professor, que auxiliava os acadêmicos na definição do tema de pesquisa e na elaboração do respectivo projeto. Na continuidade, em outro semestre, de acordo com a área de conhecimento de investigação, os projetos eram orientados por outros professores do Curso.

A partir de 2014, mudou-se a dinâmica da disciplina de Estudos Dirigidos para Conclusão de Curso. O estudante passou a elaborar seu projeto de pesquisa diretamente com o orientador, ou seja, o acadêmico escolhe o professor orientador de acordo com a temática de estudo.

Tem se percebido que há graduandos do curso de Educação Física - Licenciatura que chegam ao final do curso e optam por fazer o projeto de pesquisa direcionado à área não escolar, campo de atuação de profissionais de Educação Física - Bacharelado. Não é uma exigência que todos os licenciados pesquisem temas relacionados à área escolar, pois compreende-se que a Educação Física, enquanto campo científico, consolidou-se a partir da aproximação e contribuições de várias disciplinas-mãe (Fisiologia do Exercício, Biomecânica, Psicologia do Esporte...) e que foi fortemente influenciada pelo campo esportivo, como explicita Bracht (2003), ao discutir a constituição 
do campo acadêmico da Educação Física, o que, de certa forma, dificulta a definição da especificidade do campo de pesquisa. Isso possibilita que, mesmo a Educação Física estando na área de conhecimento das Ciências da Saúde, ela dialogue com as Ciências Humanas, por exemplo.

Portanto, entende-se, nesse estudo, que a Educação Física é "um campo de conhecimento que se caracteriza como uma prática pedagógica e científica, que tematiza e/ou investiga, com intenções pedagógicas, elementos da cultura corporal" (REZER, 2014, p. 28). Porém, as razões que levam o acadêmico de um curso de licenciatura a pesquisar um tema da área não escolar é uma questão que desperta curiosidade, uma vez que estão se formando professores, sendo o TCC parte desse processo formativo.

Assim, o objetivo desse estudo é identificar e analisar fatores que influenciam os acadêmicos de um curso de Educação Física - Licenciatura na definição da escolha do tema de estudo do seu TCC. Este estudo se justifica pelo fato de buscar subsídios que auxiliem a compreender a relação que os estudantes estabelecem entre a pesquisa e sua formação profissional.

\section{A iniciação à pesquisa no Ensino Superior e na Educação Básica}

Entendemos por pesquisa a atividade básica da ciência, mas, também, a atividade investigativa do cotidiano. É a pesquisa que alimenta a atividade de ensino e a construção do conhecimento. A pesquisa refere-se à atividade de investigação e ao despertar da curiosidade.

A pesquisa científica pode ser definida como um conjunto de processos sistemáticos e críticos aplicados ao estudo de algum assunto ou fenômeno. A diferença entre a abordagem quantitativa e qualitativa é que a qualitativa se aprofunda no mundo dos significados, enquanto, na quantitativa, o cientista trabalha com estatísticas visando a criar modelos abstratos ou a descrever e explicar fenômenos que produzem regularidades, que são recorrentes e exteriores aos sujeitos (MINAYO et al., 2008).

A pesquisa busca ultrapassar o senso comum, que é uma reconstrução da realidade do nosso dia a dia através do método científico. Pesquisar no meio acadêmico é elaborar um projeto que requer domínio de técnicas de coleta de dados e domínio metodológico por parte do pesquisador.

Demo (2008, p. 23) diz que:

As grandes universidades não são conhecidas pelo seu nome e sim pelas grandíssimas mentes brilhosas que lá se formam. Os grandes autores conhecidos foram também grandes estudiosos profissionais, eles podem ter participado e escutado muitas aulas, mas o seu processo formativo se deu na base do seu esforço e busca pela sabedoria. Pesquisar e elaborar são grandes habilidades imprescindíveis. Todos esses autores hoje vistos como grandes mestres da literatura, eles foram também alunos e pessoas "com 
pouco conhecimento" porém se dedicaram a fazer o que lhes dava prazer e hoje construíram uma enorme pirâmide de respeito e sabedoria à sua volta, foram muito além de uma pesquisa simples, eles criaram e inovaram, foram atrás de muitos dados para se construir uma nova ideia tanto sobre a sociedade como fora.

Contudo, para este autor, é necessário superar a visão unilateral que considera pesquisa apenas estágios sofisticados, representados pelos produtos solenes do mestre ou doutor. A pesquisa precisa ser internalizada como atitude cotidiana, sendo seu distintivo mais próprio, o questionamento reconstrutivo. "Por 'questionamento', compreende-se a referência à formação do sujeito competente, no sentido de ser capaz de, tomando consciência crítica, formular e executar projeto próprio de vida no contexto histórico" (DEMO, 2007, p. 10).

Dessa forma, pesquisar é uma atitude fundamental na educação de sujeitos críticos e autônomos. Conforme Demo (2007, p. 16), "a educação não é só ensinar, instruir, treinar, domesticar, é, sobretudo, formar a autonomia crítica e criativa do sujeito histórico competente".

A pesquisa ajuda a esclarecer muitas dúvidas acerca de um tema em que há interesse em aprofundar mais o conhecimento, além de libertar o sujeito para que ele siga por caminhos que antes não conseguiria, ou seja, nos dá mais autonomia. Por isso, para Demo (2007, p. 34):

A Educação pela pesquisa supõe muitos cuidados e decisões de professores e alunos. Um desses cuidados é que o professor deve orientar seu aluno permanentemente para que ele consiga se expressar de maneira fundamental, sempre pensando em exercitar o questionamento, exercitar a formulação própria e reconstruir autores e teorias cotidianas à pesquisa.

No Ensino Superior, nos cursos de graduação, muitas vezes, a iniciação à pesquisa é abordada tendo em vista instituir a responsabilidade da formação dos acadêmicos exclusivamente para as disciplinas de Metodologia da Pesquisa e TCC.

A disciplina de Metodologia da Pesquisa vai muito além de preparar para um TCC. Abordam-se modos de análises de dados, técnicas de estudo, leituras e redação científica, pensamento e escrita compatíveis com o rigor científico, técnicas de produção de conhecimento válido, elaboração de projetos de pesquisa e suas etapas, fontes de pesquisa, métodos de abordagem e procedimentos de coleta de dados, tipologias de pesquisa, entre outros tópicos, tudo isso enriquece a jornada do estudante em seu percurso universitário (RUIZ, 2009).

Contudo, a responsabilidade pela formação relacionada à iniciação científica não pode ser restrita à disciplina de Metodologia da Pesquisa. É um processo que deve ocorrer em todas as outras disciplinas. Além disso, a 
iniciação à pesquisa deve começar na Educação Básica, como Demo (2007) defende; porém, nem sempre isso acontece.

Uma pesquisa realizada com 373 alunos do $3^{\circ}$ ano do Ensino Médio dos municípios de Lajeado, Estrela, Arroio do Meio e Encantado, RS/BRA, em 2008, Neuenfeldt et al. (2008) investigaram o uso da Internet como fonte de pesquisa e como ela é utilizada para a elaboração de trabalhos escolares. Nela constatou-se que:

[...] predomina tendência à reprodução do conhecimento, pois $9 \%$ deles falaram diretamente que copiam e colam e $52 \%$ que juntam diversos textos copiando e colando o que interessa o que não difere muito. Ler e interpretar reescrevendo é citado por $14 \%$ e ler e escrever novo texto a partir das ideias apresentadas, por $21 \%$. (NEUENFELDT et al., 2008, p. 10)

Em virtude dessas evidências, outra pesquisa feita por Neuenfeldt et al. (2011) com professores que ministram as disciplinas de iniciação científica na graduação demonstra a preocupação deles com a falta de formação na Educação Básica relacionada à pesquisa. Essa falta de formação na Educação Básica preocupa, pois ela deveria ser a base para os alunos que vêm para o Ensino Superior.

Por isso, para Demo (2007), educar pela pesquisa é um dos grandes desafios da Educação Básica. O fazer e refazer pela pesquisa é o que melhor distingue a educação escolar de outros tipos e espaços educativos, tais como: a família, a roda de amigos, o ambiente de trabalho etc. Esses outros espaços podem, ocasionalmente, recorrer à pesquisa, mas não com propriedade específica.

Neuenfeldt et al. (2011) dizem que, na graduação, a ênfase dada a cada um dos estudantes é diferenciada em cada curso, pois o professor busca contemplar o perfil de egresso que se quer. No entanto, percebe-se, entre os professores, uma preocupação em relação à compreensão de ciência e de pesquisa com a qual os estudantes estão se deparando no Ensino Superior. Dessa forma, as disciplinas de Metodologia de Pesquisa necessitam dar conta de questões da Filosofia da Ciência, questões normativas e técnicas e, ainda, conciliar teoria e prática. Isso representa um grande desafio para esses professores que, muitas vezes, precisam contemplar esses temas complexos em apenas uma disciplina de sessenta ou trinta horas aula.

Um dos temas que a disciplina de Metodologia da Pesquisa trata é a ética na pesquisa. A esse respeito, uma das preocupações que Neuenfeldt et al. (2011) destacam é o plágio. Ele ocorre quando o acadêmico não tem conhecimento sobre a escrita acadêmica, que é um saber técnico, mas, também, ético, que pode ter consequências no campo legal. É de ordem técnica, pois precisa-se ensinar a escrever, a fazer uso das diferentes fontes de pesquisa 
de forma correta. É de ordem ética, na medida em que se sabe fazer uso das fontes, mas se faz cópia, conscientemente. Essa é uma questão que precisa ser abordada desde a Educação Básica.

Para Oliveira (2001), o Ensino Superior, enquanto continuidade da Educação Básica, é responsável pela formação teórico-prática do aluno em áreas/subáreas específicas do conhecimento. Cabe a ele familiarizar o aluno com o referencial de base da área/subárea escolhida por este para estudo, propiciando condições de iniciar sua vida profissional e/ou seguir uma carreira acadêmica. Mas, a iniciação científica do aluno não pode ser pensada somente a partir do Ensino Superior, nem apenas por meio da pesquisa científica da qual ele participa sob orientação de um professor.

Educar pela pesquisa é uma possibilidade metodológica, ou, ainda, como Demo (2008, p. 14) descreve: "a base da educação escolar é a pesquisa e não sala de aula". A pesquisa torna o sujeito crítico e criativo; já uma aula passada e copiada não transparece nada para os alunos. A pesquisa deve ser parte da vida cotidiana do professor e do estudante, pois a educação é o processo da formação da competência humana histórica.

\section{CAMINHOS METODOLÓGICOS}

\section{Característica da Pesquisa}

Esta pesquisa de cunho qualitativo caracteriza-se como descritiva e de campo. Foi realizada em um Centro Universitário do RS/BRA. Minayo (2004) escreve que a pesquisa qualitativa responde a questões muito particulares e que ela trabalha com um universo de significados, motivos, aspirações, crenças, valores e atitudes, o que se refere a um espaço mais profundo das relações, dos processos e dos fenômenos, os quais não podem ser quantificados. Triviños $(1987$, p. 128) comenta que a pesquisa qualitativa é essencialmente descritiva, pois "as descrições dos fenômenos estão impregnadas dos significados que o ambiente lhe outorga, e como aquelas são produto de uma visão subjetiva, rejeita toda a expressão quantitativa, numérica, toda medida". Além disso, conforme Triviños (1987), a maioria dos estudos no campo da educação é de natureza descritiva, tendo como foco principal conhecer o desejo de uma comunidade, seus traços característicos, seus problemas etc.

\section{Contexto e Sujeitos do estudo}

Essa pesquisa foi realizada em 2016, em um Centro Universitário do RS / BRA, com estudantes do curso de Educação Física - Licenciatura. A população do estudo foram todos os matriculados, no semestre 2016B, na disciplina de Estudos Dirigidos para Conclusão de Curso e no Trabalho de Conclusão de Curso, perfazendo um total de 38 acadêmicos. Participaram da pesquisa 12 acadêmicos, que aderiram voluntariamente. 


\section{Instrumentos e procedimentos de informações}

Foi aplicado um questionário. Os acadêmicos receberam um Termo de Consentimento Livre Esclarecido, leram e assinaram a autorização para uso das informações. O questionário foi entregue em mãos para os acadêmicos no horário das aulas das disciplinas de TCC. Àqueles que não tiveram presentes nesses momentos, o questionário foi encaminhado por e-mail. Obteve-se o retorno de 12 participantes.

Optou-se pelo questionário, pois, de acordo com Gil (2012), ele possibilita atingir um grande número de pessoas, mesmo que estejam dispersas, pois pode ser enviado por correio ou por várias outras formas.

As respostas dos participantes foram a principal fonte de informações da pesquisa. Por isso, depois de estruturado, o questionário foi validado através de uma testagem com dois professores formados em Educação Física - Licenciatura. Esse teste serviu para identificar possíveis falhas nas questões elaboradas, tais como: complexidade das questões, imprecisão na redação, entre outros.

Além disso, também se analisou o Projeto Político Pedagógico do curso de Educação Física - Licenciatura dos investigados, a fim de analisar como a iniciação à pesquisa se faz presente no curso em disciplinas como Metodologia da Pesquisa.

\section{Análise das Informações}

A análise das informações se deu através do levantamento de unidades de significados, organizadas numa única categoria de análise: fatores que influenciam a escolha do tema do TCC. A discussão dessa categoria foi fundamentada na triangulação entre as informações coletadas no campo de pesquisa através do questionário, com o referencial teórico e as interpretações dos pesquisadores. A seguir apresentamos os resultados e a respectiva discussão.

\section{FATORES QUE INFLUENCIAM OS ACADÊMICOS DO CURSO DE EDUCAÇÃO FÍSICA, LICENCIATURA NA DEFINIÇÃO DA ESCOLHA DO TEMA DO TCC}

Ao buscar informações sobre a atuação dos acadêmicos do estudo na área escolar e não escolar, pode-se verificar, no Gráfico 1, que $41 \%$ dos acadêmicos já atuaram na área escolar durante a graduação; $17 \%$ atuaram na área não escolar; $25 \%$ atuaram nas duas áreas; $17 \%$ nunca atuaram em nenhuma delas. 
Gráfico 1 - Campos de atuação dos sujeitos do estudo

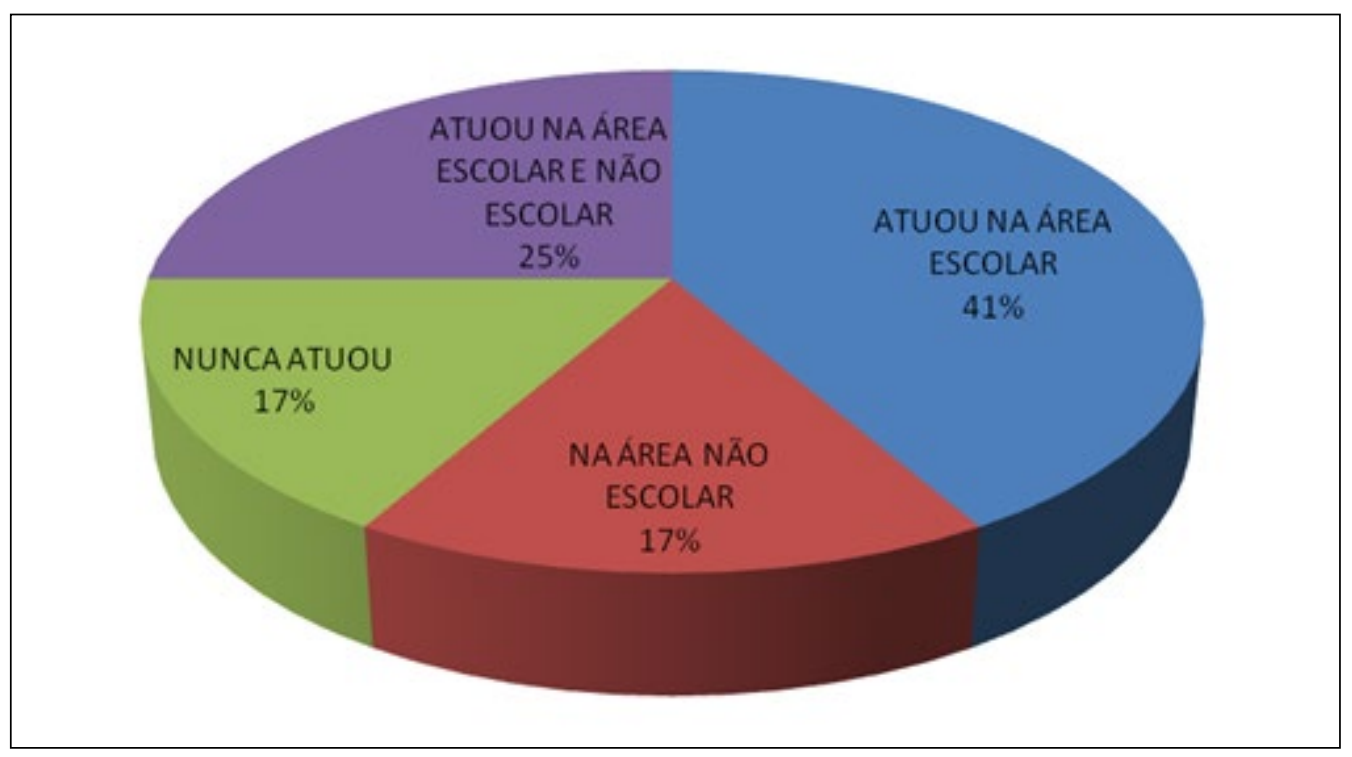

Fonte: elaborado pelos autores.

Em relação à área não escolar, os locais e práticas corporais contemplam atividades aquáticas, esportivas e de preparação física. Isso se evidencia nas falas a seguir: "Hidroginástica, natação, atividades com grupo de idosos" (Questionário 5, TCC1); "Estagiária nas escolinhas de vôlei" (Questionário 7, TCC1); "Academia de musculação, preparador físico em escolinhas de futebol" (Questionário 9, TCC2). A área escolar também foi citada pelo mesmo acadêmico, "Atuei como professor de Educação Física na escola com Educação Infantil, Anos Iniciais e Ensino Médio" (Questionário 9, TCC2). Ainda foram acrescentadas as possibilidades de atuação como "Estagiária de Educação Física na escola e no PIBID" (Questionário 7, TCC1).

A partir desses dados, considera-se importante a reflexão sobre a análise do campo de atuação dos acadêmicos durante a graduação. O campo de atuação é um dos fatores determinantes da constituição da identidade profissional. É através da identidade que nos percebemos, que conseguimos nos desenvolver na carreira profissional e na vida, o que também pode vir a refletir na escolha do tema do TCC no final do curso. Pode-se dizer que a identidade é a forma como um professor se diferencia do outro; é uma construção de si mesmo em que experiências vividas vão se agregando com o processo formativo durante a graduação.

O saber não é uma coisa que flutua no espaço: o saber dos professores é o saber deles e está relacionado com a pessoa e a identidade deles, com a sua experiência de vida e com a sua história profissional, com 
as suas relações com os alunos em sala de aula e com outros atores escolares (TARDIF, 2012, p. 11).

O acadêmico, quando ingressa na Universidade, já fez uma escolha profissional, porém tem pouco conhecimento da área, o que vai aprofundar com o ensino, a pesquisa e a extensão. Uma experiência fundamental durante a graduação para conhecer o campo de atuação são os estágios supervisionados. Os participantes dessa pesquisa, por serem concluintes do curso, já realizaram no mínimo um estágio, ou seja, já experimentaram a docência no contexto escolar.

Gariglio (2010, p. 12) diz:

O mundo dos professores aparece como uma diversidade ao plano das identidades profissionais afirmadas. Tal diversidade é marcada fortemente pelas condições de trabalho realmente efetuadas pelos diferentes subgrupos de professores, pelas missões educativas específicas e redefinidas por eles. Os professores se constituem na realidade numa multiplicidade de subgrupos com a sua própria identidade, a sua experiência do sistema escolar, vivendo tensões com outros subgrupos e com o quadro institucional.

Dessa forma, considerando que os participantes da pesquisa são de um curso de Educação Física - Licenciatura, ao analisar a relação dos temas de TCC com o campo de atuação, encontrou-se que 58,4 \% se enquadram na área escolar e $41,6 \%$ se enquadram na área não escolar. No quadro abaixo (quadro 1), apresentam-se os títulos dos TCCs, nos quais se identificam os temas de estudo de cada sujeito dessa pesquisa.

Quadro 1 - Títulos dos TCCs e relação com o campo de atuação da Educação Física

\begin{tabular}{|l|l|}
\hline Área Escolar & Área não escolar \\
\hline Treinamento funcional e escola & $\begin{array}{l}\text { Processo de avaliação/avaliativo das } \\
\text { categorias de base dos clubes de futebol da } \\
\text { primeira divisão do RS }\end{array}$ \\
\hline $\begin{array}{l}\text { A motricidade fina realizada na Educação } \\
\text { Infantil irá contribuir para o processo de } \\
\text { alfabetização }\end{array}$ & $\begin{array}{l}\text { Pilates para idosos, avaliação das valências } \\
\text { motoras de idosos participantes }\end{array}$ \\
\hline $\begin{array}{l}\text { As causas que levam os alunos a não } \\
\text { quererem participar das aulas de } \\
\text { Educação Física }\end{array}$ & $\begin{array}{l}\text { Qualidade de vida de adolescentes } \\
\text { praticantes e não participantes de } \\
\text { programa de iniciação esportiva }\end{array}$ \\
\hline Dança para adolescentes na área escolar & $\begin{array}{l}\text { Análise da percepção da qualidade de vida } \\
\text { de atletas femininas de categoria de base }\end{array}$ \\
\hline
\end{tabular}




\begin{tabular}{|l|l|}
\hline Área Escolar & Área não escolar \\
\hline $\begin{array}{l}\text { Corpo gordo, infância e e } \\
\text { contemporaneidade }\end{array}$ & $\begin{array}{l}\text { Corrida estacionária em meio aquático: } \\
\text { as respostas das frequências cardíacas em } \\
\text { imersão e em diferentes temperaturas de } \\
\text { água }\end{array}$ \\
\hline $\begin{array}{l}\text { Abordagem do tema transversal meio } \\
\text { ambiente nas aulas de Educação Física }\end{array}$ & \\
\hline $\begin{array}{l}\text { Futsal nas aulas de Educação Física: as } \\
\text { aprendizagens das meninas }\end{array}$ & \\
\hline
\end{tabular}

Fonte: elaborado pelos autores.

No Quadro 1, percebe-se que há graduandos do curso de Educação Física - Licenciatura, direcionando seus temas de TCCs para a área não escolar, campo de atuação que pertence ao bacharel em Educação Física.

Ao perguntar aos participantes da pesquisa sobre as justificativas da escolha do tema de TCC, encontramos como motivos: atuar nesse campo/ área; ser atleta (história de vida/afinidade); melhorar as práticas pedagógicas escolares e inovar; e relação com o(s) estágio(s).

Em relação ao campo de atuação, um acadêmico comenta: "Escolhi este tema porque é pouco abordado na área da Educação Física. Atualmente, o Pilates vem ganhando força na mídia e na 'boca do povo'. Então fiquei curiosa para analisar os idosos e qual seu progresso" (Questionário 5, TCC1).

A escolha do tema e sua conexão com a História de Vida é evidenciada em acadêmicos que vivenciaram na infância e na adolescência algo relacionado a ele, tal como o fato de o acadêmico ter sido atleta quando mais jovem: "Fui atleta profissional de futebol e atuo na área desde o $1^{\circ}$ semestre, tendo assim afinidade com o futebol" (Questionário 2, TCC2).

Ainda, relacionado à História de vida, muitos acadêmicos colocaram suas justificativas abordando suas vivências com a Educação Física, quando eram alunos do Ensino Fundamental e Médio. Outros, por terem uma proximidade, desde criança, com profissionais do esporte, o que despertou a curiosidade sobre o tema, bem como, o desejo de trabalhar futuramente nesta área.

Assim, percebe-se que a escolha do tema do TCC se aproxima das razões que os acadêmicos dão ao serem perguntados sobre a escolha do curso. Figueiredo (2004, p. 7) diz que a escolha do curso de Educação Física é determinada por experiências sociocorporais:

Ao recebermos os "calouros", a cada início de semestre, entre os anos de 1988 e início de 2000, quando ocupava o cargo de coordenadora de um curso de Educação Física (CEFD/UFES), fazíamos a habitual pergunta: por que escolheram cursar Educação Física. Foram várias 
as respostas obtidas. Algumas podem ser situadas no campo da estratégia de ação, quando os alunos respondiam que a escolha se dera pela maior facilidade de ingresso em relação a outros cursos. Outras respostas estavam relacionadas às experiências no campo familiar, quando os estudantes respondiam que houve um incentivo de irmãos ou mesmo de pais que são professores de Educação Física. A maior parte das respostas afirmava que a escolha pelo curso decorria da identificação com o esporte de alto nível ou pela própria experiência escolar voltada ao esporte, ou seja, pela experiência social que o aluno mantinha com essa área do saber.

Assim, compreende-se que a escolha do tema do TCC também passa pelas experiências sociocorporais, seja como atletas ou estudantes, anteriores ao curso, pois a construção dessa identificação dos alunos não ocorre somente na Universidade, mas fora dela também. A História de Vida de cada aluno acompanha-o durante a formação e a construção de sua trajetória profissional. A vivência na área fora do meio acadêmico também ajuda o acadêmico na escolha da profissão que ele vai querer seguir. Ainda, a experiência no campo profissional vai auxiliar na opção pela permanência ou não na profissão.

Outro fato evidenciado nos questionários é a busca por melhorar as práticas pedagógicas escolares, pois, quando se atua na área, já se pode ter uma ideia do que os alunos necessitam e o que pode ser interessante proporcionar a eles, a fim de despertar o gosto e o interesse pela Educação Física. No questionário 10, encontramos: "Escolhi este tema porque é na infância onde tudo começa, as primeiras impressões, influências, a formação de personalidade e entre outros fatores. E por este motivo acredito na relevância de realizar meu estudo com crianças, para saber como elas se relacionam" (TCC2).

Neuenfeldt e Pace (2008) também mencionam que a escolha pelo curso de Educação Física dá-se por diferentes motivos, entre os quais está o desejo de promover mudanças em relação à forma como vivenciaram as aulas de Educação Física escolar. Essas memórias dizem respeito a exclusões que sofreram em razão do estereótipo (gordo/magro), gênero ou pouca habilidade técnica nos esportes, ou mostraram-se descontentes com a forma como as aulas eram conduzidas. A procura do curso por esses acadêmicos relaciona-se com o desejo de propor experiências mais ricas e propor uma Educação Física inclusiva, ou seja, para todos, respeitando as individualidades de cada um.

No entanto, há de se pensar como o curso de graduação influencia o estudante em relação à formação para a iniciação à pesquisa. Ao perguntar sobre quais disciplinas tratam da iniciação à pesquisa, foram citadas as de Metodologia da Pesquisa, Gestão do Esporte, Estágio, Voleibol, Esportes Aquáticos, Estudos Dirigidos para Conclusão de Curso, Leitura e Produção de Texto e Futsal. Houve alunos que citaram todas as disciplinas e também alunos que não citaram nenhuma disciplina. Abaixo, o gráfico com as disciplinas: 
Gráfico 2 - Disciplinas citadas que trabalharam com iniciação à pesquisa e que contribuíram para definir o tema do TCC

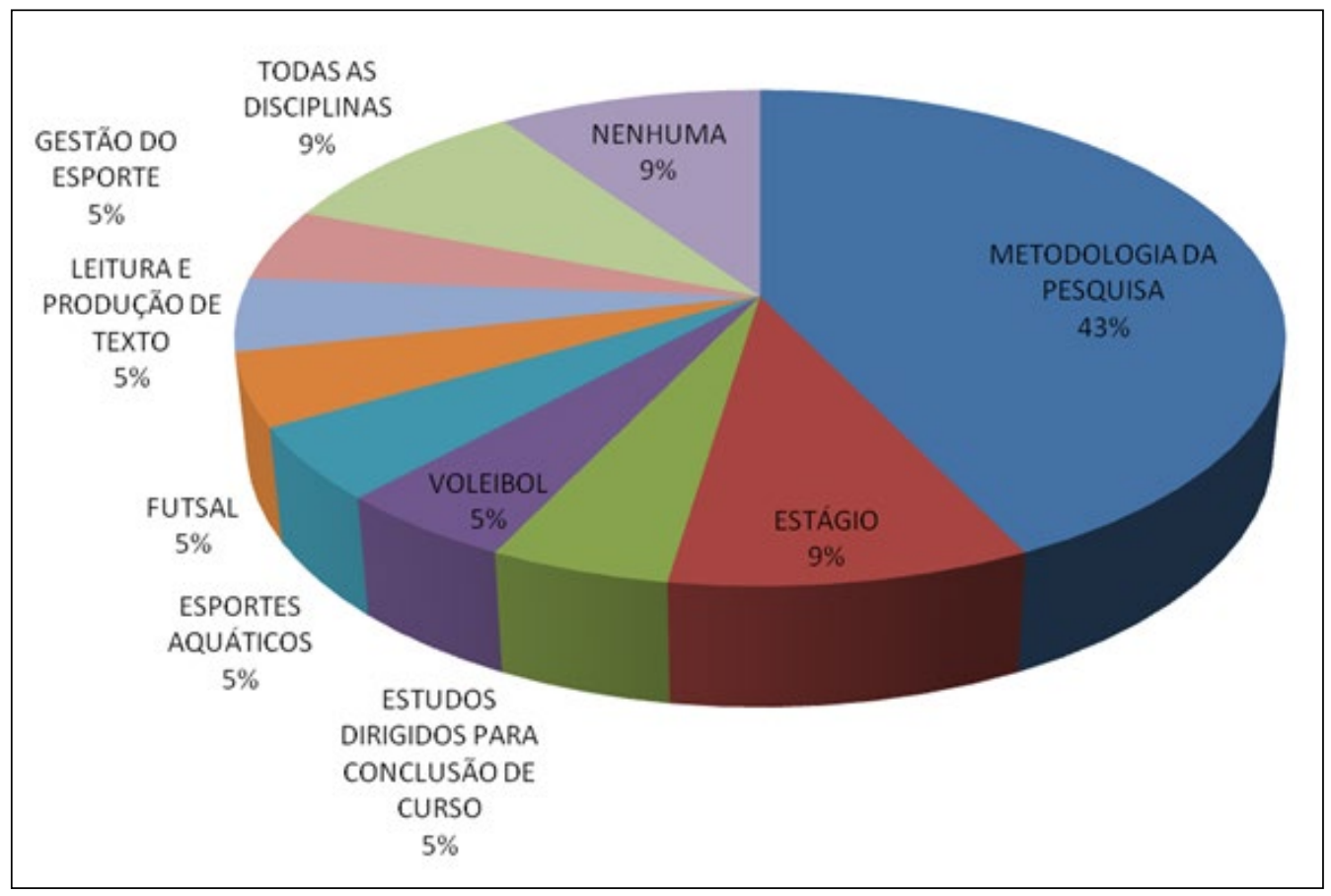

Fonte: elaborado pelos autores.

O gráfico acima mostra que a disciplina de Metodologia da Pesquisa foi a mais citada. Na ementa dessa disciplina consta: "Diferentes olhares do pesquisador na investigação. Estudo de aspectos básicos do processo de pesquisa e da ciência. Aspectos formais na elaboração e apresentação de trabalhos científicos. Exigências éticas e posturas do pesquisador na produção do conhecimento" (PPC, 2015).

Os conteúdos trabalhados na disciplina são: paradigmas das ciências; metodologia científica; ética em pesquisa; elaboração e apresentação de projetos de pesquisa; métodos, técnicas e procedimentos de pesquisa em ciências; pesquisa quantitativa e qualitativa; regras básicas da redação científica; normas acadêmicas de apresentação de trabalhos científicos; estudo das diversas metodologias de pesquisa. Portanto, o objetivo é desenvolver habilidades para a elaboração de um projeto de pesquisa, além do domínio das normas da ABNT; uso das novas tecnologias da comunicação, especialmente a internet; compreensão da estrutura e distinções entre monografia, artigo e paper; e seleção de materiais confiáveis para auxiliar na pesquisa.

Neuenfeldt et al. (2011), ao investigar os professores que atuam na disciplina de Metodologia da Pesquisa, evidenciou uma expectativa muito 
grande por parte dos estudantes universitários nessa disciplina em relação ao processo de iniciação à pesquisa no Ensino Superior. Nesse sentido, para melhorar ou dar continuidade ao trabalho iniciado na disciplina, foram apresentadas pelos autores, duas sugestões: a) ter disciplinas que ampliem as discussões éticas, que, nesse caso, seria uma disciplina obrigatória e comum a todos os cursos, tal como Filosofia da Ciência; b) que cada curso, em todas as disciplinas, assuma a responsabilidade pela continuidade da formação científica e ética. Essas duas sugestões demandam grande articulação entre os professores e destaque nos Projetos Pedagógicos dos cursos (NEUENFELDT et al., 2011).

Além da disciplina de Metodologia da Pesquisa, nesse estudo, outras foram citadas, tais como: Gestão do Esporte, Estágio Supervisionado, Voleibol, Esportes Aquáticos, Estudos Dirigidos para Conclusão de Curso, Leitura e Produção de Texto e Futsal. Algumas dessas disciplinas citadas relacionam-se diretamente com a escolha do tema de TCC, conforme pode ser observado no Quadro 1, sem, obrigatoriamente, tratar da iniciação à pesquisa. Contudo, essas disciplinas, em algum momento, despertaram o interesse pela pesquisa.

Além das disciplinas, foi perguntado aos acadêmicos se o curso proporciona outras formas ou espaços para a formação da iniciação à pesquisa, além do TCC. Foram destacados a elaboração de artigos, estágios e o PIBID: "Sim, na realização de artigos" (Questionário 6, TCC1); "A construção de propostas para estágio" (Quesionário10, TCC2); "PIBID, também foi muito destacado entre outros fatores" (Questionário TCC).

Os acadêmicos reconhecem que a produção de artigos, a construção de propostas para estágio, como, também, o PIBID tem ligação com a iniciação à pesquisa. Dessa forma, percebe-se que a preocupação em despertar para a pesquisa é desenvolvida em outros momentos ao longo do curso e que a definição do tema de TCC depende e é influenciada por diversos fatores.

\section{CONCLUSÃO}

Nesse estudo, constatou-se que a definição do tema de estudo para o TCC no curso de Educação Física - Licenciatura é influenciado pela relação do acadêmico com o campo de atuação; pela experiência vivida como atleta; pela afinidade com o tema; pelo desejo de melhorar as práticas pedagógicas escolares ou inovar; e pela experiência do estágio supervisionado. Entre os temas estudados, predominam os relacionados à Educação Física Escolar, mas, também, há os da área não-escolar.

Assim, podemos nos perguntar: Licenciatura tem que pesquisar só escola? Entendemos que o TCC é parte constituinte da formação; logo, pesquisar um tema possível de ser relacionado com o futuro campo de atuação é relevante. Porém, a área não escolar também interessa à escola. Se olharmos para a Educação Física enquanto campo de conhecimento, ela é muito mais 
ampla do que os conhecimentos do campo escolar. Limitá-la à escola é restringir o olhar sobre o mundo. Contudo, fazer a relação da pesquisa com a escola fortalece a formação docente.

Evidenciou-se, também, que há necessidade de que a formação para a iniciação à pesquisa seja contemplada de maneira transversal ao longo do Curso. Disciplinas como Metodologia da Pesquisa e TCC são fundamentais para tratar da especificidade da temática. Outras disciplinas também foram relacionadas à formação para a pesquisa, mas essa questão merece uma nova investigação no sentido de compreender por que os acadêmicos percebem a pesquisa em algumas disciplinas e, em outras, não; bem como, a forma de trabalho dos professores do curso de Educação Física com a pesquisa/investigação em suas aulas.

A pesquisa é um processo educativo que contribui para o futuro professor apropriar-se de uma cultura de investigação problematizadora da sua prática profissional. Entende-se que a pesquisa se desenvolve como um processo continuado, que não se limita às disciplinas específicas, mas como um comportamento indispensável ao longo de todo o curso. A busca e a produção de conhecimento pela pesquisa devem ser exercícios constantes nas disciplinas e na prática formativa.

Como consequência, espera-se que o futuro professor de Educação Física seja autor do seu próprio fazer pedagógico. Essa atitude se alicerça no processo de ação-reflexão-ação, que é exercitado ao longo do processo formativo. A pesquisa permite aos futuros profissionais de Educação Física que interpretem novos cenários, compreendam o seu contexto de atuação e desenvolvam ações didático-pedagógicas de acordo com a realidade dos seus alunos.

\section{REFERÊNCIAS}

BRACHT, V. Educação Física: cenas de um casamento (in)feliz. 2 ed. Ijuí: UNIJUÍ, 2003.

DEMO, P. Educar pela pesquisa. 8. ed. Campinas: Autores Associados, 2007.

Metodologia para Quem Quer Aprender. São Paulo: Atlas, 2008.

. Metodologia da Investigação em Educação. Curitiba: Ibpex, 2013.

FIGUEIREDO, C. C. Z. Formação docente em Educação Física: experiências sociais e relação com o saber. Movimento. Porto Alegre, v. 10, n. 1, p. 89-111, janeiro/abril de 2004. Disponível em: <http://www.ufrgs.br/periodicos/periodicos-1/movimento > Acesso em: 28 set. 2016

GARIGLIO, Â. J. O papel da formação inicial no processo de constituição da identidade profissional de professores de Educação Física. Revista Brasileira de Ciências do Esporte. Florianópolis, v. 32, n. 2-4, p. 11-28, dez. 2010. Disponível 
em: <http:/ / www.scielo.br/scielo.php?pid=S010132892010000200002\&script=sci_ abstract\&tlng=pt>. Acesso em 28 set. 2016.

INSTITUIÇÃO. Plano de Desenvolvimento Institucional (PDI) - 2015-2019. 2014.

MINAYO, M. C. S. Ciência, técnica e arte: o desafio da pesquisa social. In:

(Org.) Pesquisa social: teoria, método e criatividade. Petrópolis: Vozes, 2004. p. 9-28.

NEUENFELDT, D. J.; PACE, É. A compreensão pedagógica dos acadêmicos de Educação Física da UNIATES/Lajeado/RS/BRA sobre o ensino dos esportes coletivos. In.: NEUENFELDT, D. J. (Org.). Esporte, educação física e formação profissional. Lajeado: UNIVATES, 2008. p. 83-122.

NEUENFELDT, D. J. (Orgs.). Anais do III Congresso Estadual de Educação Física na Escola: "Educação Física Escolar: O que temos a falar sobre didática?". Lajeado. 08 e 09 de maio de 2014. p. 26-35. Disponível em: <http:/ / www.univates.br/editoraunivates/publicacao/76>. Acesso em: 30/07/2014.

NEUENFELDT, D. J. et al. A cibercultura e os alunos do ensino médio: apontamentos e reflexões. Lecturas: Educación Física y Deportes. Revista Digital, Buenos Aires, v. 13, n. 126, p. 1-13, 2008. Disponível em: <http:/ / www.scielo.br/scielo.php?script=sci_ arttext\&pid=S1516-73132011000200003 > . Acesso em: 08 nov. 2016.

NEUENFELDT, D. J. et al. Iniciação à pesquisa no ensino superior: desafios dos docentes no ensino dos primeiros passos. Lecturas: Educación Física y Deportes. Revista Digital, Bauru, v. 17, n. 2, p. 289-300, 2011. Disponível em: <http:/ /www. scielo.br/scielo.php?script=sci_arttext\&pid=S1516-73132011000200003 >. Acesso em: 09 out. 2016.

OLIVEIRA, L. C. V. Iniciação à pesquisa no ensino superior: o novo e o velho espírito científico nas atividades acadêmicas. In: Reunião Anual da ANPED, 24, 2001, Caxambu. Anais... Caxambu, 2001. p. 1-15. Disponível em: <http://www.anped.org. br/reunioes/24/ T1181081976681.doc>. Acesso em: 17 mar. 2016.

REZER, Ricardo. Conhecimento e prática pedagógica na Educação Física escolar: aproximações com o campo da Didática. In.: FENSTERSEIFER, S. I.; NEUENFELDT, D. J. (Orgs.). Anais do 3. ${ }^{\circ}$ Congresso Estadual de Educação Física na Escola:

"Educação Física escolar: O que temos a falar sobre didática?". Lajeado. 08 e 09 de maio de 2014. p. 26-35. Disponível em: <http: / / www.univates.br/editora-univates / publicacao/76>. Acesso em: 30/07/2016.

RUIZ, Á. J. Metodologia científica: guia para eficiência nos estudos. 6. ed. São Paulo: Atlas, 2009.

TARDIF, Maurice. Saberes docentes e formação profissional. 13 ed. Petrópolis, RJ: Vozes, 20122.

TRIVIÑOS, A. N. S. Introdução à pesquisa em ciências sociais: a pesquisa qualitativa em educação. São Paulo: Atlas, 1987. 